\section{Human study participants}

We read with interest Fletcher's editorial on ethics approval for all studies involving human participants as a condition of publication, and the importance of having this done by ethics review boards as knowledgeable and unbiased third parties. ${ }^{1}$ As noted, although this approach is now standard for experimental studies, the practice for observational studies is inconsistent, and there are calls for exemption from ethics review for quality improvement, practice audits and similar endeavours.

Fletcher points to streamlined ethics review processes introduced in New Zealand and the United Kingdom. There is also a Canadian solution. Public Health Ontario has developed a process wherein all studies involving human participants receive an initial risk screening to determine the required level of ethical scrutiny. ${ }^{2}$ Similar to the New Zealand protocol with 24 questions, ${ }^{3}$ the Public Health Ontario process involves a 20 -item risk-screening tool, which sorts projects into one of four review levels: full ethics board review, a conventional delegated review process, an expedited delegated review process or no further review with periodic audit (manuscript currently under review).

This approach supports CMAJ's desire for an expanded yet balanced scope of ethics review and is broadly applicable in other settings where quality improvement and other observational studies are conducted.

\section{Donald Willison ScD, Nancy Ondrusek} PhD, John McLaughlin, PhD

Institute of Health Policy (Willison),

Management and Evaluation, University of Toronto; Public Health Ontario (Ondrusek, McLaughlin), Public Health Ontario;

Toronto, Ont.

\section{References}

1. Fletcher J. Ethical approval for all studies involving human participants. CMAJ 2014;187:91.

2. Willison DJ, Ondrusek N, Dawson A, et al. What makes public health studies ethical? Dissolving the boundary between research and practice. BMC Med Ethics 2014;15:61.
3. Screening questionnaire to determine the approval procedure. Palmerston North (New Zealand): University of New Zealand; 2014. Available: www.massey. ac.nz/massey/research/research-ethics/human-ethics/ forms-and-procedures.cfm (accessed 2014 Dec. 20).

CMAJ 2015. DOI:10.1503/cmaj.115-0028

\section{The Lyme law}

I recently read CMAJ's interview ${ }^{1}$ with Dr. David Patrick, who used words like "junk science" and "pseudoscience" regarding the diagnosis and treatment of Lyme disease. I worked as a consultant physician at the University of British Columbia's Complex Chronic Diseases Program from 2013 to 2014, a clinic formed to improve testing and treatment for patients with Lyme disease, fibromyalgia and chronic fatigue syndrome/ myalgic encephalomyelitis.

The issue in Lyme disease treatment is that there is inadequate research to lend evidence-based support to any guidelines. Certainly there is evidence that Borrelia burgdorferi persists in dogs, rats, monkeys, people and even in the test tube after antibiotic treatments. ${ }^{2-5}$

The National Institute of Allergy and Infectious Diseases (NIAID) states on its website that "additional research is needed and continues to be supported by NIAID to learn more about persistent infection in animal models and its potential implication for human disease." ${ }^{\prime \prime}$ In the absence of good evidence-based guidelines, patients are floundering and physicians are afraid to treat.

A review of the evidence ${ }^{7}$, using the GRADE system, shows all the evidence that exists (and all that is lacking) at each stage of tick bite, erythema migrans rash and chronic Lyme disease. What I appreciate about this review is that it explores the role of patient preference at each stage of Lyme disease, where clear evidence is lacking as to treatment duration.

Physicians have a duty to explore concerns about risks of long-term use of an antibiotic. In each case, we must look at the risk-benefit ratio. This is not new to the treatment of Lyme disease. In Lyme disease, we must analyze, upon tick-bite exposure, the risk of a tick carrying the disease, and of not treating a documented erythema migrans rash long enough. We must consider whether a patient is more concerned about Lyme disease prevention or about the risks of unnecessary antibiotics and adverse reactions.

It is messy work, and the research needs to be done. In the meantime, physicians are in the trenches and patients are sick. The US Centers for Disease Control and Prevention estimate 300000 US cases per year of Lyme disease, and we cannot be so naive as to think this disease stops at the US border. In 2007, only 13 cases were officially reported in British Columbia. However, a survey by the BC Centre for Disease Control in 2007 showed that 148 physician respondents ( $8.8 \%$ of their sample) had diagnosed a total of 221 cases of Lyme disease in the preceding year. ${ }^{8}$ If 221 cases were diagnosed by such a small sample of physicians, why were only 13 cases officially reported?

We are dramatically underestimating the number of cases of Lyme disease, and I am glad to see that Bill C-442 is proceeding so that we can improve research into testing and treatment of this disease. We are at a stage with chronic Lyme disease similar to where we were with HIV in the 1990s, when clinicians had to use clinical judgment to treat those who were sick while awaiting quality evidence to be published. I am hoping that Bill C-442, which has the support of the Canadian Medical Association, will allow this to happen nationally.

\section{Elizabeth Zubek BSc MEd MD}

Maple Ridge, BC

\section{References}

1. Brown C. Lyme law uses "junk science" says expert. CMAJ 2014;186:1354.

2. Hodzic E, Feng S, Holden K, et al. Persistence of Borrelia burgdorferi following antibiotic treatment in mice. Antimicrob Agents Chemother 2008;52:1728-36.

3. Straubinger RK, Summers BA, Chang YF, et al. Persistence of Borrelia burgdorferi in experimentally infected dogs after antibiotic treatment. J Clin Microbiol 1997;35:111-6.

4. Embers ME, Barthold SW, Borda JT, et al. Persistence of Borrelia burgdorferi in rhesus macaques following antibiotic treatment of disseminated infection. PLOS ONE 2012;7:e29914. 
5. Feng J, Wang T, Wanliang Shi, et al. Identification of novel activity against Borrelia burgdorferi persisters using an FDA approved drug library. Emerg Microbes Infect 2014;3:e49.

6. National Institute of Allergy and Infectious Diseases. Chronic Lyme disease. Bethesda (MD): National Institutes of Health; 2014. Available: www.niaid.nih. gov/topics/lymeDisease/understanding/Pages/chronic. aspx (accessed 2014 Nov. 19).

7. Cameron DJ, Johnson LB, Maloney EL. Evidence assessments and guideline recommendations in Lyme disease: the clinical management of known tick bites, erythema migrans rashes and persistent disease. Expert Rev Anti Infect Ther 2014;(9): 1103-35.

8. Henry B. Lyme disease: Knowledge, beliefs, and practices of physicians in a low-endemic area. Can Fam Physician 2012;58:e289-95.

CMAJ 2015. DOI:10.1503/cmaj.115-0029

\section{Syncope confusion}

Soong and colleagues' intent was to highlight the overuse of investigations, particularly neuroimaging, among patients with syncope. ${ }^{1}$ Although Soong and colleagues cited the 2009 European Society of Cardiology guideline, ${ }^{2}$ they failed to differentiate syncope from other causes of transient loss of consciousness. Syncope is caused by global cerebral hypoperfusion, and none of the listed neurologic diagnoses cause syncope.

This confusion has led to great research efforts, consensus conferences, guidelines and statements developed by the European Society of Cardiology, the Gargnano multidisciplinary consensus conference (led by internists), and the Canadian Cardiovascular Society, all of which uniformly exclude neurologic conditions causing transient loss of consciousness from syncope..$^{2-5}$

Based on current evidence, syncope is defined as a transient loss of consciousness due to global cerebral hypoperfusion characterized by rapid onset, short duration, and spontaneous complete recovery. Sadly, this article ${ }^{1}$ worsens the confusion by clearly stating that neurologic causes of syncope exist. This could cause practising physicians to include neurologic causes in the differential diagnosis for true syncope, and to not differentiate syncope from other causes of transient loss of consciousness. This is important, as the literature evidence regarding the risk of "cardiac syncope," and use of neuroimaging exist only for true syncope patients and cannot be applied to all patients with transient loss of consciousness. The authors could also have cited new evi- dence for high-risk features for "cardiac syncope" that have been summarized, based on evidence. 6,7

\section{Venkatesh Thiruganasambandamoorthy MBBS MSc, Robert Sheldon MD PhD}

Department of Emergency Medicine (Thiruganasambandamoorthy), University of Ottawa, Ottawa, Ont.; Division of Cardiology (Sheldon), University of Calgary, Calgary, Alta.

\section{References}

1. Soong C, Chen BH, Wong BM. A 62-year-old woman with syncope. CMAJ 2015;187:48-9.

2. Moya A, Sutton R, Ammirati F, et al. Guidelines for the diagnosis and management of syncope. Eur Heart J 2009;30:2631-71.

3. Sun BC, Costantino G, Barbic F, et al. Priorities for emergency department syncope research. Ann Emerg Med 2014;64:649-55.

4. Sun BC, Thiruganasambandamoorthy V, Cruz JD. Standardized reporting guidelines for emergency department syncope risk-stratification research. Acad Emerg Med 2012;19:694-702

5. Sheldon RS, Morillo CA, Krahn AD, et al. Standardized approaches to the investigation of syncope: Canadian cardiovascular society position paper. Can J Cardiol 2011;27:246-53

6. D’Ascenzo F, Biondi-Zoccai G, Reed MJ, et al. Incidence, etiology and predictors of adverse outcomes in 43,315 patients presenting to the emergency department with syncope: An international meta-analysis. Int J Cardiol 2013;167:57-62.

7. Berecki-Gisolf J, Sheldon A, Wieling W, et al. Identifying cardiac syncope based on clinical history: A literature-based model tested in four independent datasets. PLoS ONE 2013;8:e75255.

CMAJ 2015. DOI:10.1503/cmaj.115-0030

\section{The authors respond}

We thank Thiruganasambandamoorthy and Sheldon for clarifying the definition of syncope as a transient loss of consciousness due to global cerebral hypoperfusion characterized by rapid onset, short duration and spontaneous complete recovery. ${ }^{1}$ However, experts acknowledge that this approach has pragmatic limitations, particularly when applied to undifferentiated patient presentations in the emergency department. To guide clinicians in the emergency department, our approach focuses on all potential causes of transient loss of consciousness, including syncope "mimickers." We agree that stroke, transient loss of consciousness, seizure and metabolic disturbances do not represent true syncope.

Christine Soong, MD MSc, Benjamin H. Chen, MD

Department of Medicine (Soong), University of Toronto; Division of General Internal Medicine (Soong), Mount Sinai Hospital, Toronto, Ont.; Department of
Medicine (Chen), Queen's University, Kingston, Ont.; Lennox \& Addington County General Hospital (Chen), Canadian Society of Internal Medicine (Soong, Chen), Ottawa, Ont.

\section{Reference}

1. Sun BC, Costantino G, Barbic F, et al. Priorities for emergency department syncope research. Ann Emerg Med 2014;64:649-55.

CMAJ 2015. DOI:10.1503/cmaj.115-0031

\section{Group A streptococcus}

It was gratifying to read that the authors of this commentary ${ }^{1}$ on group A streptococcus mention the significant rate of colonization versus infection. Surprisingly, this was not mentioned in the related research article. ${ }^{2}$ This continuing uncertainty, so appropriate in science, highlights the need for the art of medicine - the art in which clinicians dance with the complexity of uncertainty, balance their sense of whether the child is quite ill ("toxic") or otherwise medically fragile, converse with parents to assess their resourcefulness and preferences, and balance all of this with the public health issues. I would appreciate a review of the implications of the treatment of carrier states, with respect to group A streptococcus in particular.

Another $C M A J$ paper, ${ }^{3}$ examining the potential harms of the use of amoxicillin and amoxicillin-clavulanic acid, also surprised me by treating the two drugs as if they were similar. I understand that the latter is one of the broadest spectrum agents, and one I reserve for very specific situations. I am of the old school, and I still do not even use amoxicillin for group A streptococcus, preferring penicillin $\mathrm{V}$ (which is often not even available in the suspension form).

\section{Andre C. Piver MD}

Nelson, BC

\section{References}

1. Science M, Bitnun A, McIsaac W. Identifying and treating group A streptococcal pharyngitis in children CMAJ 2015;187:13

2. Cohen JF, Cohen R, Levy C, et al. Selective testing strategies for diagnosing group A streptococcal infection in children with pharyngitis: a systematic review and prospective multicentre external validation study. CMAJ 2015;187:23-32.

3. Gillies M, Ranakusuma A, Hoffmann T, et al. Common harms from amoxicillin: a systematic review and meta-analysis of randomized placebo-controlled trials for any indication. CMAJ 2015;187:E21-31. 